\title{
NACIÓN Y CULTURA ${ }^{1}$
}

\author{
Félix Martínez Bonati
}

Dejando atrás el ideal nacionalista de la Modernidad y su "postmoderna” desconstrucción, hace falta reconsiderar la necesidad y la contingencia, así como las limitaciones y virtudes, de la Nación moderna. La vocación nacional, unificante, está en inevitable conflicto con los particularismos culturales y la segregación étnica de subcomunidades. Hasta cierto punto crítico, conflictos y diferencias enriquecen la vida de una comunidad nacional, pero más allá de él no son manejables, ni siquiera en la sociedad democrática tolerante, y, obviamente, tienden a ser destructivos. La integración de todos los habitantes del territorio en una cultura nacional óptimamente mínima

Félix Martínez Bonati. Estudió literatura y filosofía en Chile y Alemania, donde obtuvo su doctorado en filosofía. Ha sido profesor de la Universidad de Chile, la Universidad Austral de Chile, las Universidades de Iowa e Illinois y de Columbia University, de la cual es profesor emérito, y profesor visitante en Goettingen y Princeton. Fue rector de la Universidad Austral de Chile entre los años 1962 y 1968. Autor de una vasta obra sobre teoría literaria que incluye, entre otras publicaciones, La Estructura de la Obra Literaria (traducida al inglés con el título Fictive Discourse and the Structures of Literature y publicada por Cornell University Press); La Ficción Narrativa (Su Lógica y Ontología); El Quijote y la Poética de la Novela (también publicada en versión en inglés, Don Quixote and the Poetics of the Novel, por Cornell University), y La Agonía del Pensamiento Romántico: Cuatro Ensayos sobre Nuestra Situación Intelectual (Editorial Universitaria, 2004).

${ }^{1}$ Texto de la lección inaugural del Congreso de Humanidades celebrado con ocasión de los cincuenta años de la Universidad Austral de Chile, en Valdivia, el 2 de septiembre de 2004. 
es un bien social demostrable. Su realización suscita profundos dilemas morales. Pero, para empezar a resolverlos, hay que pensar bien en qué ha de consistir esta integración. A menudo se falsifica hoy el sentido de la transculturación hacia la cultura occidental moderna porque se tiene de ésta un concepto inadecuado. Sin claras nociones de las realidades y metas implicadas no puede darse, ante diversidades étnicas, una política razonable.

\section{$\mathrm{H}$}

ablaré de la idea de Nación ${ }^{2}$ y su cultura, y secundariamente del fenómeno de comunidades heteroculturales, a veces naciones, que viven bajo un Estado moderno occidental. No me referiré a las particularidades históricas y socioculturales que este tema tiene hoy en Chile. Consideraré el problema sólo en los términos más generales, como se presenta en muchas partes del mundo: minorías culturales, a veces además raciales —o comunidades mayoritarias, pero culturalmente no asimiladas- que viven en sociedades sustentadas por la cultura europea moderna. Se funda este ensayo en la convicción de que una reflexión letrada del no especialista, no obstante tener un fundamento empírico difuso y no sistemático, puede ayudar a despejar el marco conceptual de los debates.

Aclaro que no consideraré los problemas que se relacionan con el espectro de las clases sociales de una comunidad nacional. Doy por supuesto aquí que hay procesos, buenos y malos, que afectan a una Nación en su conjunto y que, como es natural, tocan de manera y grado diversos a los que ocupan diversas posiciones sociales. Estas diferencias no son parte de mi tema de hoy. Tampoco lo es la diferencia entre una Modernidad socialista y una capitalista, no por poco importante sino porque pertenece a otro plano de la realidad histórico-social. Diré también que sólo haré uso incidental de la distinción de nacionalismo y patriotismo. Se suele entender lo primero como una disposición agresiva y destructora y lo segundo como una virtud pacífica y constructiva. Valga la distinción por su connotación normativa, pero sus implicaciones denotativas me parecen confusas. Usaré ambas voces por lo general como cuasisinónimos. Finalmente, debo solicitar indulgencia para el hecho de que uso centralmente aquí, y sin distinguirlos de modo expreso, los términos “cultura” y “civilización”, cuyas

${ }^{2}$ Escribo Nación con mayúscula para designar a las entidades históricas en que una comunidad humana, no necesariamente homogénea de origen y cultura, convive en un territorio delimitado y propio y constituye en él un Estado. Distingo así a la Nación de la nación concebida como comunidad étnica, de raza y cultura, que puede carecer de autonomía política y definición territorial. 
ambigüedades son conocidas y se han multiplicado en exceso en los últimos tiempos. Es poco el análisis que puedo dedicarles en estas breves consideraciones. Inicialmente, como significados de uso corriente, estas nociones son vagas, pero todo lo contrario que vacías, y son las puertas que nos dan acceso al recinto de esta problemática. Espero que lo que expondré les confiera indirectamente una mayor determinación.

En el clima intelectual de lo que se ha llamado la Postmodernidad (que es sólo la más reciente modulación de la Modernidad occidental), difundido en las últimas tres o cuatro décadas, ha adquirido prominencia una inconsistente, pero reiterada denuncia de la civilización europea como forma de injusticia radical. A la vez se ha generalizado la tesis de que las Naciones, entronizadas en un territorio con fronteras discriminatorias, unidas jurisdiccionalmente en un Estado independiente de completa soberanía, sostenidas por un sentimiento patriótico comunitario y empeñadas en perfeccionar su homogeneidad cultural, son un producto contingente y ya idealmente obsoleto de circunstancias económico-tecnológicas de la Modernidad. Serían las Naciones modernas una figura, pues, además de reciente, muy transitoria de la existencia colectiva, que se estableció en la mente de los ciudadanos gracias a la forja progresiva de una mitología nacionalista en cada caso singularizada. Haciendo uso de una de esas ficciones metódicas de la filosofía política acerca de los orígenes de las sociedades humanas —a las que recurrió Platón y han recurrido, entre otros, Hobbes, Locke y Rousseau, y hasta nuestro contemporáneo Rawls-, podría resumirse así la tesis postmodernista del origen de la Nación: voluntades políticas circunstanciales, determinadas esencialmente por sus intereses económicos, dan nombre a un territorio controlable y formulan una ley de agrupación soberana de todos sus habitantes. La ley se impone mediante el monopolio gubernamental de la violencia. Pensadores esbozan entonces metas colectivas. Los poetas crean los mitos fundacionales, los artistas exaltan y decoran el entorno geográfico, oportunos teólogos entrevén un designio divino. La Nación asume la dignidad benévola y severa de la Patria. Las Naciones modernas serían esencialmente una construcción histórica, invenciones ideológicas, "comunidades imaginadas", como dice un conocido libro de ese título. La entidad Nación aparece hoy a muchos como cosa irreal, un engaño más entre los varios de nuestra falsa conciencia habitual.

Hasta mediados del siglo XX se solía pensar de otra manera. Los discursos nacionalistas de los intelectuales sostenían la esencialidad y vir- 
tual eternidad de la entidad patria. Los altibajos históricos del pasado eran concebidos como accidentes de su progreso y depuración, el camino de su autorrealización. La historia nacional elemental tenía algo de la novela formativa: el relato de sufrimientos, experiencias, triunfos y sacrificios que conducen a una madurez gloriosa. Los múltiples símbolos de la Nación llevaban el aura de lo sagrado. Se esperaba un general y espontáneo entusiasmo para luchar y morir heroicamente en el altar de la patria. Un eminente escritor español de ese tiempo nos dice que el espíritu eterno de España es visible no sólo en las obras y siglos del pueblo cristianizado sino ya en las reliquias visigodas y celtíberas, en la Hispania romana, sí, hasta en las figuras prehistóricas de las cuevas de Altamira. Ésta y otras Naciones atosigadas de su grandeza pudieron pensarse a sí mismas como momentos necesarios de la experiencia humana, como una cumbre en la marcha del Espíritu Universal.

En el universo mental de un joven reflexivo el sentimiento patrio tiende a ser ambivalente. Percibe algo dudoso en la frecuente exaltación irracional de este sentimiento, una suerte de autoengaño, la consecuencia de las prácticas paternalistas de socialización de la niñez, que nos harían víctimas mecanizadas de una manipulación política. La imagen histórica popular de las Naciones se le presenta firmemente asociada a sus guerras. La retórica nacionalista lo conmina, y las leyes del país lo obligan, a disponerse a dar nada menos que la vida en defensa de una entidad que le parece abstracta y hasta casual. Si mis padres hubiesen emigrado al país vecino, medita, habría tenido que estar dispuesto a luchar a muerte por mi potencial enemigo de ahora. Los motivos de disputa entre las Naciones le parecen insignificantes, meros pretextos para desatar las energías obtusas de quienes son incapaces de empresas superiores, para encauzar resentimientos, obtener riquezas o ilusorias o corruptoras, no producto del trabajo creador, y para envanecer a un costo horrendo de sufrimientos colectivos a las elites políticas y militares.

Casi automáticamente se vincula hoy al nacionalismo con el imperialismo, el genocidio y la guerra. Las más devastadoras de la Historia han sido, en efecto, las del siglo recién pasado entre las Naciones modernas de Europa, Norteamérica y Asia. Por añadidura, la estructura afectiva del ideal nacional es peculiar: se espera del ciudadano que ame superlativamente a su patria, pero, aunque ello va bien con una permanente irritación por las deficiencias de la acción colectiva, ¿cómo puede dejar de detestar a muchos que son parte viviente de ella? Luego, ¿cómo articular esa devoción a la patria con las que lo unen a su religión, a sus ideales humanitarios y su sentido de justicia, a sus sueños político-universales? ¿Son conciliables 
estos imperativos o estamos ante contradicciones insuperables que sólo admiten soluciones de ocasión, que no pueden ser razonadas? Comprensiblemente, el desmontaje del ideal de la Nación y la disipación de su aura sagrada encuentran en sujetos sensibles una recepción bien predispuesta.

Pero no se trataría sólo de la crisis intrínseca de la idea y el sentimiento de Nación. La fatalidad histórica de la globalización diluiría los límites nacionales en lo económico, debilitaría el poder de los gobiernos y por eso impulsaría a los sujetos a buscar refugio y sentido de la existencia en identidades aparentemente más profundas o más reales que las patrias: la identidad étnica o la religiosa, o en agrupaciones ideológicas o profesionales, o en asociaciones de exclusivo interés material, sean éstas nacionales o transnacionales. Una consecuencia de todo ello sería que se invierte el imperativo de homogeneidad cultural y se formula el ideal de sociedades que abarcan múltiples comunidades, diferentes en credos, modos de vida, valores y lenguajes.

El descrédito académico de la Modernidad y de su ideal nacionalista ha ido a la par con la exaltación de las identidades étnicas y de las culturas no occidentales. Frente a la tendencia unitaria y culturalmente homogeneizante del Estado nacional moderno, se celebran los valores de sociedades multiculturales y heterogéneas. La tribu, el clan, las naciones no unidas por un Estado sino por sus tradiciones culturales o su raza parecen entidades más altamente estimables que el monolito nacional-estatal. Consecuentemente, se combate la homogeneización cultural que tendría lugar dentro de la civilización occidental. La torre de Babel de la Modernidad dejaría su lugar, no a la maldición sino a la celebración de la multiplicidad de los lenguajes.

Hasta aquí el rápido resumen de esta coyuntura ideológica.

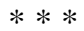

Haré sólo una breve glosa a la popular condenación de Occidente que mencioné al comienzo como frecuente motivo del Postmodernismo. Muchos de quienes la proclaman parecen creer que lo hacen observando esa cultura en su conjunto y desde fuera. ¿Desde dónde? ¿Desde qué plataforma conceptual y valórica? Tal vez en su mayoría esos gestos polémicos se limitan a emplazar a algunas de las instituciones, más o menos duraderas, de la herencia occidental, no a los fundamentos de su racionalidad ni a los valores del moderno individualismo ilustrado. Tanto en su lenguaje y sus formas argumentativas como por los bienes e ideales que evocan, estas críticas están sumidas por completo en la tradición intelectual de Europa. Se 
trata de nuevas versiones de los esfuerzos revisionistas y reformistas que definen esa tradición desde un comienzo y cuyas manifestaciones de autocrítica general se reiteran, diría, desde Heródoto, en el elogio de culturas ajenas, en las utopías del Renacimiento, inclusive los géneros bucólicos de la literatura, en el pensamiento de Montaigne, Montesquieu, Voltaire y Rousseau, en las concepciones revolucionarias del siglo XIX, en fin, para no prolongar esta enumeración incompletísima y apresurada, en las críticas del siglo XX al sujeto de la Modernidad. No creo imposible argüir que esta disposición tradicional se extiende hasta los cuestionamientos más radicales de Lévi-Strauss, Heidegger o Derrida, en sus críticas de la técnica moderna, de la metafísica europea o de la racionalidad sistemática.

Sólo para facilitar la recta comprensión de mi argumento debo decir que mi posición ante esta cultura es afirmativa. Ante todo, la concibo más como una modalidad creadora que como un orden de contenidos fijos. Me hago cargo de que trae consigo enormes riesgos, que su creciente complejidad probablemente exige demasiado de las varias poblaciones del planeta, y que su dinamismo e inestabilidad pueden estar llegando al grado de lo humanamente intolerable. Es probable también que su ideal igualitario, por una parte, y su ideal libertario e individualista, por otra, además de inconciliables, sean cada uno por separado autodestructivos para los pueblos que llegan a encarnar profundamente su espíritu. Pero no se logra ver una alternativa razonable. Estamos embarcados en esta civilización, cuyo hundimiento, nada imposible, sería una catástrofe del más vasto alcance, y sólo nos cabe influir en su proceso desde dentro y mínimamente.

$$
* * *
$$

Tornemos al concepto de Nación. Presentaré en lo que sigue algunas observaciones críticas sobre las tesis ideológicas que he evocado.

La visión de la riqueza de lenguajes y universos simbólicos de las múltiples culturas nos hace olvidar el hecho palmario de que traen consigo la imposibilidad de la comprensión mutua inmediata. Una comprensión que requiere traductores e intérpretes de actitudes y costumbres es manejable cuando se trata de encuentros entre individuos de diversos países, que serán ocasionales, pero en la densa interrelación de la vida nacional se dejan sentir como obstáculos mayores para la acción común. Si a la diversidad meramente lingüística se agregan diferentes normas de conducta, el conflicto subterráneo es áspero y cotidiano. No es de extrañar, por eso, que las comunidades culturales subordinadas, en muchas partes hoy —en rigor: 
dondequiera que pueden, dondequiera que tienen posibilidades territoriales y a la vez una conciencia orgullosa de su identidad, despreciativa tanto de la subalternidad como del parasitismo — aspiren a la independencia política y la autonomía estatal. En otras palabras: las comunidades culturales minoritarias o socialmente marginadas, si se sienten suficientemente fuertes y se saben en condiciones efectivas de independizarse, quieren convertirse en Naciones monoculturales. Y con ello la práctica política real de hoy parece reducir al absurdo a la ideología multiculturalista. Las naciones tienden naturalmente a alcanzar el status de Naciones-estado. Y las Naciones-estado tienden, por la lógica del sistema general de la civilización, a definirse internamente como naciones, como comunidades étnicas unitarias. Las contingencias histórico-geográficas ponen diversos obstáculos a estas voluntades y determinan conflictos clásicos, activos, hoy como ayer, en muchas partes. La Nación moderna, sin embargo, como trataré de mostrar en la parte final de esta presentación, ha sido y es un proyecto de superación evolutiva de las tensiones de la heterogeneidad. Es de preguntarse, pues, si la experiencia histórica da de veras razones para esperar la pronta desaparición de los estados modernos o la continuada vitalidad de sociedades culturalmente heterogéneas.

La sociedad multicultural es a todas luces un conjunto altamente inestable que, paradójicamente, sólo puede subsistir bajo un Estado nacional fuerte que protege a sus minorías étnicas. Aunque hay antecedentes en ciertos períodos de sociedades del pasado remoto, como en la Grecia y la Roma clásicas, el Estado protector de la diversidad se ha dado principalmente en algunas de las Naciones modernas occidentales. Es el Estado laico, neutral con respecto a las religiones y confesiones y, por eso, relativamente abstracto en su definición, que gira en torno a los ideales libertarios e individualistas de la Ilustración. Pero estos ideales de la igual libertad e independencia espiritual de cada persona, precisamente, son antagónicos a las convicciones, no, por cierto, de todas, pero sí de muchas minorías étnicas. Vemos aquí el contradictorio circuito de conceptos y manifiestas realidades que determinan la situación política contemporánea. Problema medular es, por consiguiente, que aun cuando la voluntad homogeneizante de la Nación-estado multicultural pudiese limitarse a una cultura de la libertad y la tolerancia, ella estará en conflicto esencial con culturas vivientes en su seno.

También debe ser materia de reflexión, cuando se hace la por cierto necesaria crítica de la Nación moderna, el que los conflictos bélicos nunca, ni siquiera en la Modernidad, se han limitado al enfrentamiento de Nacio- 
nes-estados. Los plurales genocidios del siglo XX han tenido motivaciones raciales y culturales. Exterminios de multitudes han obedecido a insanias ideológicas ajenas a diferencias de Nación. La disposición a la violencia entre grupos de cualquiera manera marcados como diversos parece darse en todas partes y en todo tiempo conocido. Las presuntas mínimas y remotas excepciones a esta ley parecen haber sido ilusiones antropológicas filoprimitivistas. Hacer de estructuras sociales temporales la causa de conductas humanas universales y transhistóricas ha sido un error característico del historicismo relativista contemporáneo.

Por otra parte, es de considerar también que el establecimiento de un Estado unitario efectivo suprime las varias formas de violencia organizada de grupos dentro del territorio: los conflictos de los príncipes y las ciudades, de los señores feudales, de las bandas al margen de la ley, de las confesiones rivales, de las clases económicas o grupos de interés y de los partidos. El Estado nacional no es sólo instrumento de la independencia del dominio extranjero sino también el medio de la pacificación interior. Vemos hoy en nuestro continente cómo prolifera la mortal violencia interna allí donde la unidad del Estado es precaria.

$$
* * *
$$

Debemos, en consecuencia, preguntarnos: ¿es la Nación algo tan insubstancial y fabricado como sostienen algunos? ¿Y son sus efectos para la vida de los seres humanos de veras predominantemente negativos?

Podemos convenir en que las Naciones no son entidades naturales sino históricas y en su origen no necesarias ni providenciales sino contingentes. La pregunta es si tienen algún fundamento natural y si en el curso de su historia no surgen condiciones que las convierten en una necesidad vital para sus miembros.

Hecho indudable es que las Naciones modernas, constituidas como Estados, disponen de un territorio delimitado y que la gran mayoría de sus miembros vive dentro de esos límites. Ello determina, casi por la sola física de la proximidad, que la interrelación de los habitantes entre ellos ha de tener una densidad y frecuencia muchísimo mayor que la que puedan tener con los habitantes de los países vecinos, qué decir con los de países remotos. Los intercambios de productos y servicios los unen cotidianamente. Los lazos familiares y de amistad se forman de preferencia dentro de los circuitos locales y nacionales. Clima, calamidades naturales, económicas o políticas los afectan, aunque en grado diferente, en común. Con el pasar de 
los años y los siglos, los contactos repetidos tienen que dar lugar a ciertos usos y hábitos comunes, buenos y malos, en alguna medida distintivos. La información que los ciudadanos reciben, tanto medial como directa, es en gran parte de exclusiva pertinencia nacional. Las figuras públicas cuya acción más directamente los afecta pasan a constituir parte de una circunstancia política y cultural extendida a todos los sujetos mínimamente informados. Aun si faltase toda acción destinada a forjar una conciencia nacional, la pura mecánica de estas relaciones tiene que ir creando una comunidad de experiencia, un pequeño mundo compartido y diferente del de otras Naciones.

Todo esto es tan obvio como real, más aún, inevitable.

Pero la unidad de la Nación no se limita a la cohesión mecánica y pasiva que acabo de señalar. La Nación es también un proyecto consciente, naturalmente difuso, de vida en común. Es una empresa cooperativa. Tal empresa requiere la disposición de todos a conductas convenidas, y por ello una fuerza de adhesión subjetiva y un universo intelectual colectivo que hace posible la intercomunicación y la acción común efectiva.

Sin duda, ése es el espacio para las invenciones y los mitos nacionales populares. Pero, más básicamente, es el espacio de la cultura nacional, realidad que presenta grandes dificultades para su descripción y análisis. La comunidad efectiva de los ciudadanos no puede darse si no hay un mundo compartido de nociones, imágenes, ideales y experiencias superiores. Cuando digo "cultura nacional", sin embargo, no sugiero que ella sea una creación completa de cada comunidad histórica. Muy poco de ella es la hechura de cualquiera Nación tomada separadamente. En nuestro caso, nos hemos legítimamente apropiado de una tecnología, de sistemas jurídicos y económicos, de una ciencia, de tradiciones religiosas, filosóficas, literarias y artísticas de proveniencia principalmente europea. La idea y la realidad misma de Nación está conformada por esa cultura asumida. Pero nos hemos apropiado de esta cultura de modo cada vez más profundo y por ello cada vez más creador y, donde cabe, distintivo. Es nuestra cultura, vivimos de ella y contribuimos a su vitalidad.

Es necesario, para erigir el sentido de solidaridad comunitaria, que la cultura de un país, aunque de substancia, en lo más, cosmopolita y en parte universal, no distintiva, se perfile como nacional y que la idea y el sentimiento de la Patria encarnen en ella. La cultura nacional tiene sin duda un carácter normativo. Se espera de todos los que viven en un país que conozcan y respeten los principios de su convivencia, que compartan los saberes 
y los valores básicos que posibilitan su intercomunicación y su colaboración.

Entre las condiciones naturales que dan fundamento a las comunidades nacionales está la profunda e irreductible inclinación atávica del individuo a incorporarse a grupos solidarios y potencialmente beligerantes. El cálido sentimiento de pertenecer a esta o aquella comunidad va siempre unido al de hostilidad, sea primitivo o muy civilizado, hacia las otras comunidades del mismo tipo, que se definen como rivales. Tomar partido, comprometerse, parecen a veces ser imperativos éticos. Dante pone en el Infierno a los que, sin otro pecado, han cultivado una neutralidad tibia, y el Existencialismo ensalzó como acto de libre decisión y autenticidad metafísica lo que tal vez sea más bien una necesidad zoológica. Llevamos dentro una máquina de preferir, dijo Ortega, y, como siempre, su metáfora es más honda de lo que parece a primera vista. Que el ser humano sea un animal político, tendría que significar no sólo que, para vivir, debemos asociarnos con otros, sino también contra otros. Menciono esto porque creo que, si amamos la paz, debemos desconfiar de nuestras inclinaciones gregarias - no abandonarlas, que de todos modos es imposible, sino tenerlas sujetas a la disciplina crítica.

En todo caso, no es la Patria la única comunidad de que nos sentimos parte. También, en lo menor, la familia, la ciudad o región, la institución en que trabajamos, nuestro partido político, el gremio o la asociación profesional, hasta, para muchos, el club deportivo, así como, en lo supranacional, nuestra Iglesia, la Cultura, la Humanidad o, como nos sugiere Edward Wilson, la comunidad toda de los seres vivientes. La imaginación literaria o cinematográfica y la sensibilidad ecológica hacen ver que aun estas totalidades al parecer sin rivales - la Humanidad en su conjunto, la vida del planeta - pueden despertar una disposición combativa. Muchas comunidades, pues, son, a la vez, las nuestras. Nuestra incorporación a ellas obedece no sólo a nuestra necesidad objetiva de protección y ayuda mutua en el grupo solidario sino también a nuestra necesidad de activa organización y afirmación subjetivas, para las que no basta identificarnos con un modelo de vida privada y profesional. Cada individuo asume para sí un complejo y contradictorio atado de identidades o vinculaciones edificantes.

Es claro que no todas estas comunidades tienen el mismo peso en nuestra vida. Las hay de las que podemos desprendernos sin mucha pena. 
Pero las hay que son afectivamente irrenunciables y pueden enfrentarse en terribles conflictos - trágicos en sentido estricto, como lo muestra Sófocles en su Antígona, entre la devoción familiar y la ley de la polis, o, como hemos visto en nuestro tiempo, entre la conciencia moral del cristiano y la lealtad patriótica.

Objetivamente, la Nación es una comunidad de tamaño crítico. Es la comunidad capaz de existencia independiente y de acción conjunta y organizada. Su sentido está por consiguiente unido a los fines de vivir con plenitud y en libertad. Es cosa, pues, no de afectos menores sino de ser o no ser. Hay algo profundamente serio en esta entidad, que no se da en algunas de las otras comunidades que he mencionado.

De lo dicho puede desprenderse que la Nación es, en verdad, una construcción instrumental en su origen. Pero que está lejos de ser una creación arbitraria, ya que presupone una población de gente afín, capaz de intercomunicación eficaz, que comparte un entorno geográfico y un horizonte ideal. Y una vez constituida, la Nación enriquece progresivamente la substancia de su unidad práctica y espiritual con el ejercicio del convivir sostenido de sus miembros, siempre en alguna medida excluyente de la experiencia de otros pueblos. Es una comunidad de existencia y acción; para el individuo, una fatalidad —aunque, si bien en poco, puede influir en ella y alterarla, para bien y para mal.

La patria es un ente peculiar. Por una parte, todo lo que se encuentra en su territorio y es vida y obra de su población es parte de ella. Por otra, es esencialísimo el que está en cierto modo por encima de los partidos y sus antagónicas ideologías, así como de las religiones y confesiones. Virtud constitutiva de la idea de patria es que ella debe unirnos a todos por encima de nuestras diferencias de credos, intereses y convicciones. De ahí que la imagen de la patria se compone de extremos: de un lado, lo más concreto - los aires, las luces, los paisajes urbanos y naturales, los amigos y conocidos, los usos característicos, los individuos célebres de la historia nacional; en suma, un mundo familiar y pintoresco. Del otro, un proyecto comunitario de lo más abstracto, una vaga idea de libertad y grandeza. Entremedio queda la prosa de las divisiones y disputas, el grueso de la existencia política.

Análoga es la entidad "cultura nacional". También aquí el concepto abarca primero todo lo que es parte no sólo de nuestra creación propia sino de las tradiciones, principalmente occidentales, que adoptamos. Pero riguro- 
samente imperativo para todos como núcleo último de la cultura nacional es sólo la lengua practicada y normativa, un circunstancial universo común de referencia, un puñado de saberes elementales y un mínimo de credos obligatorios: en esencia, el respeto en general de la ley democráticamente convenida y en especial de los derechos humanos fundamentales, con sus deberes constitutivos. Tal reducción de la cultura absolutamente exigible de todos a un mínimo normativo es lo que define al Estado libertario moderno. Esta cultura de la tolerancia permite la coexistencia, si bien no de todas, de muchas variedades intelectuales, éticas y religiosas. Tiene tal cultura una capacidad absorbente muy diferente del proselitismo tradicional, pues no demanda conversión religiosa o ideológica substantiva. Las diferencias de credo y opinión pueden florecer vigorosamente en su seno. Puede advertirse que este carácter de la cultura de la Nación moderna, que acaso impresiona como demasiado formal y hasta vacía, es, precisamente por su relativa pobreza de contenidos y su énfasis en procedimientos, una condición de las libertades de pensamiento y expresión - y que no existe otra especie política que posea esta cualidad.

Pero, sin embargo, la cultura nacional, aun en su reducido núcleo, es menos abstracta que la idea de la patria como vago proyecto comunitario de libertad y grandeza. Por ello, su poder abarcador es menor. Pues habiendo llegado históricamente a ser una cultura del individualismo libertario, quien se asimila a ella tendría que renunciar a parte de su cultura tradicional, a su dogmatismo autoritario, al paternalismo opresivo de la mujer, y, en lenta erosión involuntaria, a diversas creencias y sentimientos, usos y costumbres. No es sorprendente, entonces, que esta cultura de las Naciones modernas libertarias encuentre aun en ellas decidida resistencia. Son actualísimos los debates sobre el Preámbulo de la nueva, y primera, Constitución europea, acerca de si debe o no hacerse una mínima excepción a su carácter laico e incluir una referencia al fundamento cristiano de la cultura del continente. No menos actuales las controversias en los Estados Unidos sobre la separación de Estado y Religión, el uso de plegarias y símbolos religiosos en las escuelas, y semejantes. También en este caso parece que no sólo la acción humana es problemática y racionalmente incontrolable sino que ya la misma idea de una cultura nacional libertaria es intrínsecamente aporética.

La idea de Nación, llena, pues, de tensiones intrínsecas, une pragmáticamente a la idea concreto-abstracta de patria con la idea máxima y mínima de cultura nacional. 
El sujeto, dijimos, siente a las comunidades a que pertenece como suyas. Forman parte de su identidad íntima. El amor a la comunidad propia se funde con el amor propio. El sujeto se sentirá rebajado en su ser si su Nación es humillada, exaltado en su orgullo personal si ella triunfa. Ello da a veces lugar a funestas inflaciones del yo patriótico, pero las patologías megalómanas no son privativas del sentimiento nacionalista, y por lo tanto no es éste su causa.

Aunque aflora de modo irregular en las diversas circunstancias de la vida y lo echamos de menos en la conducta diaria de muchos, el sentimiento patriótico existe y suele ir junto a una natural rectitud. El patriotismo tiene su realidad básica en que el sujeto, en su intimidad, está hecho de materia nacional. No tenemos una vida espiritual radicalmente independiente de nuestra acumulada experiencia cotidiana. Y ésta está saturada de mundo local. En consecuencia, en la medida en que uno se quiere a sí mismo, quiere, aunque no lo sepa, a su patria.

Curiosa entidad la patria. Y curiosa cosa nuestra vida, que se compone de tales partes.

Entro a la parte final de mi disquisición. La prosperidad y aun la existencia de la Nación suponen una adhesión activa de sus ciudadanos. Y esto significa ante todo una densa interacción constructiva de unos con otros. Los ciudadanos viven en una comunidad de intercomunicación y comprensión, lo cual supone una cultura común mínima. Que la unidad cultural de la Nación, en particular lingüística, es un bien desde el punto de vista de la eficacia de la acción colectiva en el caso de emergencias mayores, y de las relaciones singulares de los ciudadanos en el trato diario, me parece estar más allá de toda discusión. La unidad nacional —entendido que se trata del Estado de derecho democrático- es un bien tanto para la subjetividad íntima, que tiene que nutrirse del mundo-vivido patrio, como para el sujeto político-económico (cada uno de nosotros) a cuyos intereses la Nación sirve como instrumento de acción colectiva. Del grado crítico (óptimo, no máximo) de la unidad de la Nación depende su eficacia. Hablo de su eficacia para fines nada menores, como mantener la paz externa e interna, el imperio de la ley y la justicia, posibilitar el bienestar relativo de todos, prevenir y paliar sufrimientos y miserias, ensanchar el campo de los debates e ideas, proteger la investigación científica y el mejoramiento tecnológico, y asegurar la libertad religiosa y personal. Hemos visto que la Na- 
ción es una entidad substancial y no arbitraria en la medida en que sus miembros comparten lenguajes y básicos valores, imágenes, hábitos e ideas - contenidos culturales que los hacen elementalmente comprensibles unos a otros y, dentro de esos límites, predictibles y confiables.

Esto los distingue de quienes, para la comunidad dada, son espiritualmente extraños. Diversidades étnicas marcadas, naciones dentro de la Nación, naturalmente, reducen el alcance de la comunicación nacional y con ello la eficacia de la comunidad en su conjunto. En este respecto, la diversidad étnica es evidentemente un mal social. Pero en otro sentido, si viven como sociedades genuinamente autónomas, las comunidades heteroculturales constituirían un bien altísimo como medios de conservación y desarrollo de formas de vida, pensamiento y sensibilidad que, en circunstancias imprevisibles, pudiesen ser salvadoras — variedades culturales de más feliz adaptación. Estos bienes — unidad nacional y variedad de culturas - sólo son antagónicos dentro de una sociedad multicultural, y, por eso, ésta tiene que sopesarlos y decidir una política acerca del dilema que presentan.

Hay en este terreno numerosísimas incógnitas. ¿Puede hablarse, y en qué respectos, de culturas superiores e inferiores? ¿Es deseable una Humanidad culturalmente unificada? ¿Cuál sería la definición mínima de esa cultura y cuál la anchura admisible de su diversidad? Estos dilemas, que pueden parecer a primeras excesivamente teóricos y ajenos a la realidad histórica concreta, operan inexplícitamente bajo toda la política contemporánea.

Sólo puedo tocar ahora un punto de esta vasta problemática. Voy a presuponer, para los fines del análisis, que, dentro de esa unidad cultural de la Nación —que lleva en sí un mínimo, pero substancial código absolutamente exigible de todos y que define al Estado democrático y libertario-, se quiere positivamente la integración de las comunidades heteroculturales que viven en su territorio y que, por las razones que sea, no están dispuestas o en condiciones de asumir, adquiriendo un territorio propio, autonomía estatal, independencia nacional.

¿Cuál es la legitimidad moral y cuáles son las consecuencias espirituales de una política de asimilación de tales grupos minoritarios a la cultura occidental moderna del Estado? Supongamos que una adaptación voluntaria y feliz al mundo tecnológico del trabajo mejora sus condiciones materiales de vida. ¿'No traerá consigo la occidentalización laboral del sujeto la pérdida para él o ella de los elementos de identidad personal y de grupo, y de la riqueza de espíritu que reside en su patrimonio tradicional? ¿No es esta transculturación una tragedia para el individuo y eventualmente para la $\mathrm{Hu}$ - 
manidad en su conjunto por el empobrecimiento que implica la desaparición de sistemas completos de experiencia?

La Historia está llena de estas tragedias colectivas e íntimas, menos producto de la persuasión amistosa o la aculturación voluntaria que de la violencia y el temor, como la cristianización de América o la conversión de los judíos españoles, acontecimientos que sentimos cercanos, y otros del pasado más reciente, como la oficialización e inculcación del MarxismoLeninismo en los países de la esfera soviética o del Maoísmo en la Revolución Cultural china. Aunque ha habido de antiguo mentes tolerantes y ejemplares —el padre Las Casas es aquí un ejemplo pertinente-, es una virtud de la Modernidad ilustrada el que tales empresas de conversión forzada repugnen hoy a la sensibilidad mayoritaria.

A muchos, la persuasión amistosa a abrir la mente a la cultura moderna puede parecer también una insidia. Piensan que tendría lugar una disimulada substracción de la identidad del así converso y que este mal es incomparable. La progresiva pérdida de la lengua ancestral, de costumbres y creencias, el alejamiento de sus divinidades y la descomposición de su visión de la naturaleza, serían inevitables y no podrían ser compensados. Con un esfuerzo educacional decidido el sujeto podría conservar, dentro del horizonte de la Modernidad, ese mundo espiritual autóctono, pero éste quedaría para él como puesto entre paréntesis, transubstanciado, menos vivo, si vivo del todo.

Pero ¿cuál es, en este preciso sentido, la naturaleza de nuestra identidad de sujetos presunta y básicamente occidentales? ¿De qué manera vivimos nuestra cultura nacional? Pues bien, aunque esta afirmación puede sorprender a primera vista, no de otra manera que la del extraño que es transculturado a nuestro espacio espiritual. Nuestra relación con las fuentes originales de nuestra tradición sufre de un distanciamiento constitutivo. Lo estable y siempre actual de nuestra cultura es sobre todo formal: una modalidad del diálogo, más que sus contenidos; métodos del pensar, más que sus resultados. Una creatividad impaciente e iconoclasta. Una disposición a cambiar de prácticas e ideas, si hay para ello razones o impulsos de la sensibilidad. Una voluntad de transformación mejoradora de las circunstancias, abierta a futuros sólo imprecisamente imaginables. Una valoración enfática de la individualidad personal que la substrae a los modelos normativos y convencionales de ayer. Toda materia de tradición se hunde rápidamente en la memoria histórica. La mayor parte de nuestras costumbres, nuestras creencias, nuestros modos de trabajo, son inestables. 
Pero — se dirá — ¿no tenemos una tradición religiosa sostenida, vetusta y viva, un canon literario y artístico notablemente estable, clásicos del pensamiento, un saber enciclopédico acumulado y disponible, decantados ideales políticos, una tradición jurídica vigente en sus principios? Así es, pero éste es un tesoro que en gran parte de su contenido, sin perder su validez, se aleja de nosotros y sólo se lo recupera transformado. El cristiano que hoy lee serenamente el Antiguo Testamento, y aun el Nuevo, debe toparse con algunas imágenes, ideas y sentires que han de parecerle irredimiblemente arcaicos, inadmisibles ya para su sensibilidad moral y para su sentido de lo real. Es grande la distancia que media entre la fe del creyente culto de nuestro tiempo y la de los escribas de sus textos sagrados. A esta creciente distancia respondía ya la vieja tradición de la reinterpretación alegórica y responden todavía, de otro modo, los literalismos exacerbados de algunas sectas, empeñadas en deshacer imaginariamente la evolución del intelecto. ¡Qué decir de los dioses de Homero o de Virgilio, vivos como están estos autores para nosotros en sus textos y en su perdurable influencia! Sus dioses son ya desde mucho convencionales figuras retóricas, curiosidades, en el mejor caso símbolos enigmáticos. Y, ya que mencionamos los idiomas ancestrales, ¿cuántos de nosotros leemos a los fundadores de nuestra tradición espiritual en sus propias lenguas?

Las fuentes de nuestra cultura se alejan de nosotros —no digo ya cronológicamente, lo que es obvio, sino espiritualmente, por efecto de nuevos modos de pensar, nuevos conocimientos, alteraciones de la sensibilidad. Importa mucho, por cierto, que incesantemente recuperemos, en la medida de lo posible, a los clásicos próximos y remotos, pues ello determina la profundidad y la orientación de nuestro esfuerzo. Sin embargo, estas vueltas atrás nos empujan hacia adelante, porque ése es el espíritu que encontramos en las fuentes. El extraño, entonces, que se incorpora a esta cultura, establece esa misma relación de pérdida y conservación con su propio ancestro - y puede enriquecer con él el espacio espiritual común en que ahora se encuentra.

Es posible que al invitar al hermano extraño a unirse con nosotros en nuestra cultura, incurramos sin querer en un error en desmedro suyo. Hay tanto imprevisible en los efectos de la acción humana. Pero en todo caso no estaríamos pidiendo de él un sacrificio espiritual en esencia diferente del que nuestra cultura, constitutivamente, por su naturaleza, nos impone en todo momento. ¿Qué otra conducta cabe, si no la conservación evolutiva de los bienes culturales en que estamos dinámicamente sumidos? Un tradicionalismo a ultranza, la detención del movimiento intelectual, es una utopía 
(una utopía negativa) o la seña de la muerte del espíritu —una cultura de la repetición, del rito sin trascendencia, de las formas vaciadas de su creatividad original. De seguro que no queremos esto para nosotros. Significaría, entre otras cosas no poco importantes, renunciar a la mayor aventura humana, la del conocimiento, inseparable hoy de la ciencia y la tecnología modernas. ¿Podemos querer esto para nuestros semejantes? Verdad es que pocas comunidades culturales parecen estar detenidas en un estado museal, que pudiera ser el sueño de algunos antropólogos. Tal vez todos los grupos humanos viven en un proceso de experiencia progresiva. Pero tampoco querríamos dejarlos en un camino de lenta y acaso extraviada evolución cognoscitiva sin un gesto solidario, una llamada de atención.

Los dilemas morales de la relación intercultural son en verdad complejos y delicados.

Pienso, pues, que la Nación, pese a todas las rarezas y casualidades de su constitución natural e histórica, y sus intrínsecas tensiones conceptuales y afectivas, es una entidad substancial y necesaria, tanto en la acepción de esta palabra que indica lo fatal e inescapable como en el sentido de lo que hace falta, y es, hasta donde puede anticiparse, imprescindible, tanto para la subjetividad individual como para la supervivencia de las comunidades que de cualquier modo han llegado a compartir una situación y un destino. La patria es una singularidad real y nuestro afecto por ella es natural y justificado. Pienso también que la unidad cultural de la Nación es un imperativo político, aunque su perfeccionamiento nos pone ante muy serios dilemas morales.

¿Se desprende de estas abstractas elucubraciones alguna conclusión que pudiese determinar políticas relativas a la relación de la comunidad nacional de una sociedad democrática moderna con minorías, o mayorías marginadas, heteroculturales que viven en su territorio? Si mi raciocinio es tendencialmente válido, la máxima, bastante obvia, sería ésta: Toda medida que tenga por previsible consecuencia un mayor aislamiento cultural involuntario de esas comunidades debe ser evitada. Toda medida que posibilite la voluntaria asimilación de los grupos marginados a la cultura nacional común ha de ser apoyada.

Es claro que la aplicación de una máxima tal a medidas específicas no sería siempre inequívoca. Pero mi propósito en esta exposición no ha sido formular recomendaciones precisas para políticas que no pueden sino ser 
de gran dificultad y requieren ingente estudio. Lo que he querido hacer es esbozar la tarea de una reflexión analítica sobre las nociones de Nación y cultura nacional que contribuya mínimamente a disipar algunos errores conceptuales y esclarecer los términos del debate. Nuestro trabajo, por definición académico, es a la vez aclarar y complicar la visión de las cosas. No para que se posterguen indefinidamente las decisiones políticas sino para que se llegue a ellas con adicional preparación. 